\title{
Redes de indignación y esperanza Manuel Castells
}

\author{
Alianza Editorial, Madrid, España, 2012, 296 págs.
}

\author{
José Sánchez Parga
}

Centro Andino de Acción Popular, Quito, Ecuador. Email: jsparga@yahoo.com.ar

\section{Manuel Castells: un elogio emocional e inofensivo de las movilizaciones de protesta}

Cuatro observaciones preliminares sirven para enmarcar una lectura crítica de la obra reciente de Manuel Castells, Redes de indignación y esperanza.

En primer lugar este género de elogio exaltado e inofensivo de las movilizaciones de protesta actuales en el mundo ha dado lugar en muy poco tiempo a una amplia literatura, pero también ha suscitado no pocas críticas, ya que se trata por general de estudios y trabajos realizados al calor de las experiencias de dichas protestas, y recurriendo a un género muy periodístico o ensayista. La advertencia de Slavoj Zizek, de que estas protestas impotentes e inofensivas terminen enamoradas de sí mismas y celebrando anualmente sus aniversarios, no ha impedido una avalancha de textos con tonos utópicos y superlativos. ${ }^{1}$ A este género de obras pertenece la de Castells: pretendo que ésta sea mi aportación a la comprensión de los movimientos sociales en red como precursores del cambio social en el siglo XXI (p.34).

En segundo lugar, aunque Castells considera haber tomado distancia de su experiencia en la participación de las movilizaciones de protesta, no parece haberlo logrado por dos razones principales: primero, porque para tomar una distancia que pudiera objetivar una experiencia subjetiva, no sólo hubiera sido necesario despojar tal experiencia de sus cargas afectivas y emocionales, lo que el autor no hace, sino también disponer de un referente teórico capaz de garantizarle suficientes dispositivos críticos y explicativos de los fenómenos estudiados, y de los cuales el autor tampoco ha dispuesto, por las razones que veremos más adelante; segundo, porque paradójicamente Castells se remite a su experiencia de mayo 68, creyendo que ahora como entonces todo era posible; lo que la historia demostraría que fue un error. Más bien sería muy interesante comparar los acontecimientos de mayo 68 con las actuales movilizaciones de protesta, analizando cómo la fuerza y producción imaginarias gestadas en ambos acontecimientos fue equivalente a su ineficacia histórica: el poder semántico de los slogans fue impotente para lograr algunos de los cambios deseados o esperados. 
En tercer lugar, aunque Castells dedica su obra a Touraine, mi padre intelectual teórico de los movimientos sociales, sorprende que a excepción de una sola nota (p. 227, n. 1), donde refiere a su propia perspectiva teórica, al análisis y teoría tourainianos sobre los movimientos sociales, el autor nunca tenga en cuenta las principales conceptualizaciones de Touraine, como se demuestra a continuación.

En cuarto lugar, si Castells no logra tomar distancia de su experiencia y participación en las protestas, ni tampoco asume los presupuestos teóricos de Touraine, y deposita una extraordinaria capacidad de cambio de las movilizaciones de protesta, es porque el principal referente del autor, el que opera desde el trasfondo de toda esta obra, es su gran teoría de las redes sociales y de la sociedad en redes (network society); siendo a partir de ella que trata de explicar las protestas, cómo si el cambio que la comunicación en redes imprime a la sociedad moderna hiciera que las redes sociales sirvieran de fundamento y fuerza a las movilizaciones de protesta. ${ }^{2}$

Finalmente la obra de Castells se encuentra toda ella muy ambientada por un izquierdismo académico, huérfano de discursos y sin una militancia política orgánica, que busca desesperadamente nutrirse de cualquier sitio, tema o movida: ya sea el microcrédito o la economía solidaria, los derechos de la naturaleza, la vida buena, el decrecimiento todo lo que suene alternativo se convierte ya en un tópico o estrategia de izquierda. Esto explica el entusiasmo del autor de llevar a las aulas el tema y problemática de las protestas, lo que se vuelve un leit motiv de todo el libro. Y todo ello ungido por la esperanza (título del libro!) de que tras las protestas el paisaje político (americano) ya no volverá a ser el mismo. ${ }^{3}$

\section{Movimiento social o movilización de protesta}

El principal problema que plantea la obra de Castells es que confunde movimiento social y movilización de protesta. Un movimiento social responde siempre a un determinado sector social (movimiento indígena, barrial, campesino, obrero), que se constituye en actor de un movimiento reivindicativo, y por consiguiente democrático, ya que sus demandas sociales pueden ser representadas políticamente, y sus conflictos gobernables. ${ }^{4}$

Esta conceptualización fundamentalmente tourainiana de los movimientos sociales es esencial en todos sus componentes, ya que permite diferenciar los movimientos reivindicativos de las movilizaciones protestatarias. Estas a) lejos de convocar un determinado sector social, son siempre sociológicamente anónimas y heterogéneos (pueden llamarse indignados en España o forajidos en Ecuador) en su composición; b) la reivindicación es pro-activa y la protesta re-activa según la terminología tourainiana; c) mientras que las reivindicaciones reconocen y legitiman su interlocutor o destinatario, las protestas los deslegitiman y rechazan la institucionalidad de sus adversarios; d) a diferencia de los conflictos generados por los movimientos social en sí no violentos, aunque circunstancial- 
mente puedan degenerar en violencia, las protestas son en sí mismas violentas y generadoras de violencia, aunque circunstancialmente por falta de fuerza no sean violentas; e) todo ello explica por qué la protesta no es democráticamente gobernable, y más bien rechaza la institucionalidad de la democracia realmente existente. ${ }^{5}$

Se ha llegado a sostener que los movimientos sociales se politizan, sin tener en cuenta que a diferencia del movimiento social, que se rige por la razón del conflicto reivindicativo, las movilizaciones de protesta actúan de acuerdo a la lógica política del enemigo, del enfrentamiento y la oposición. Touraine es muy explícito al definir la diferencia entre el actor social y el actor político, para poder entender la radicalidad de la protesta: el movimiento oscila es el conflicto de un actor y de un adversario por la dirección en particular de las fuerzas productivas en un marco político institucional común a los adversarios un anti-movimiento social a la inversa no reconoce ningún marco común a los adversarios, que se vuelven entonces enemigos (1988:153). En otras palabras, actores y movimientos sociales compiten por los mismos recursos dentro de la misma sociedad y de su marco institucional; este conflicto los hace adversarios pero no enemigos. Las movilizaciones de protesta rechazan ese marco común institucional y entablan un enfrentamiento entre enemigos, más o menos violento, armado o desarmado.

Esto mismo se encuentra asociado a otro factor diferencial entre movimientos sociales y movilizaciones políticas: cuando un determinado grupo o sector de la sociedad se constituye en actor social por sus prácticas y discursos reivindicativos de mayor participación en la sociedad, será por la conducción de su liderazgo o de su organización, que se institucionaliza en movimiento social; no es este el caso de las movilizaciones de protesta, cuyos actores no representan un determinado grupo o sector de la sociedad, y cuyas actuaciones no están conducida por una dirigencia, liderazgo u organización, siendo más bien la fuerza inherente a la protesta, la que convoca y moviliza.

Es a partir de estos presupuestos tourainianos, y en particular de la diferencia y en cierto modo contradicción entre la sociología y política de los movimientos sociales y la sociología y política de las movilizaciones de protestataria, que se pueden cuestionar muchos de los planteamientos de la obra de Castells. Mientras que para Touraine los movimientos sociales existen permanentemente en sus prácticas y discursos reivindicativos al margen de sus manifestaciones, marcha u ocupaciones, es decir prescindiendo del repertorio o formas que adoptan en sus luchas sociales, según Castells se convierten en movimiento al ocupar un espacio urbano, ya sea mediante la ocupación permanente de plazas públicas o por las manifestaciones continuadas (p.212). Touraine precisa que el movimiento es social no porque se mueva en la sociedad sino porque mueve la sociedad, considerando que un exceso de movilización podría corresponder a un déficit de movimiento. No otra es la crítica que hace a los movimientos sociales en América Latina: actores si acción social (1988:469). 


\section{Contradicción entre reivindicación y protesta}

Si hay algo tan esencial como generalizado en las actuales movilizaciones de protesta es su diversidad de contenidos; e incluso son diversas las protestas formuladas en cada una de las movilizaciones sociales; como si cada clase, grupo, sector o actor social tuviera sus protestas o su particular versión de la protesta. Sin embargo un elemento o trasfondo común a todas las protestas seria el nuevo orden económico mundial del capitalismo financiero, que se impone como la causa última principal de todos los despojos y exclusiones, contra los que se protesta.

Pero quizás hay algo más radical y menos explícito contra lo que protestan las movilizaciones en todo el mundo: contra la dictadura de que no hay alternativa (el there is not alternative de Margaret Tatcher), imperativo con el que precisamente se legitiman la dominación y globalización del orden económico capitalista en el mundo. El problema es que las movilizaciones de protesta no logran definir cuál sería la alternativa; y nunca lograrán identificar una alternativa mientras que la fuerza de la protesta siga atrofiando las posibilidades reivindicativas. Aunque en realidad tal alternativa no existe ni es posible sino en cuanto destrucción / transformación de ese mismo orden, contra el cual se protesta.

Las actuales movilizaciones de protesta responde a una lucha contra los despojos y las exclusiones (protest again inequality), resultado de la anterior derrota de las luchas de los movimientos sociales en sus reivindicaciones por la igualdad (demand for equality). ${ }^{6} \mathrm{El}$ contexto de aquella forma de conflicto es un capitalismo distributivo en una democracia redistributiva; el contexto de este otro modelo de conflicto es la dominación neoliberal del capitalismo financiero. Esto explica la desesperación de tantos indignados y forajidos, que protestan por todo el mundo; siendo precisamente esta desesperación, y de ningún modo la esperanza, la que puede dotar de una acción eficaz y violenta a las movilizaciones sociales.

Esto explica la paradójica semántica de los slogans protestatarios: exigir todo y nada al mismo tiempo (p.184). Más aún, si no hay reales reivindicaciones posibles y consensuadas es porque la lógica y dinámica mismas de la protesta lo impiden, pues reivindicación y protesta se contradicen: la falta de reivindicaciones específicas del movimiento era uno de sus puntos débiles fundamentales (p.185). Aunque de hecho es la reivindicación, no su defecto, lo que debilitaría las protestas; cuanto más radical y total es el rechazo, menores son las condiciones para reivindicación alguna: cualquier enfoque pragmático para conseguir las reivindicaciones tendría que pasar por el sistema político, lo que sería contradictorio (p.186).

Una protesta sin reivindicaciones es una protesta desarmada y sin propuestas, y el mismo Castells incurre en esta paradoja, cuando cifra las posibles propuestas específicas en derrotar al capitalismo o restaurar el recrecimiento económico (p.127); cuando ha sido precisamente este crecimiento económico, el que siempre ha fortalecido al capitalismo. Al actual 
capitalismo financiero sólo se lo destruye sustituyendo su lógica y dinámica de concentración y acumulación de riqueza por un poder y una lógica (económicamente) distributiva y (políticamente) redistributiva. No otro es el parámetro de la solución islandesa presentado por el mismo Castells (p.47-58).

Resulta muy paradójico que las movilizaciones de protesta oscilen siempre entre un desencadenamiento de la violencia y una teatralidad festiva. Es en este caso, de una movilización social y política más ficticia que real, más teatral que eficaz (Touraine, 1988:469), que las movilizaciones de protesta, como tantos otros foros mundiales sociales o alternativos, terminan reducidos a celebraciones anuales, meetings para conmemorar el happening inaugural, donde se reproducen los slogans, sin hacer nada eficaz para que algo cambie.

\section{El teorema de la violencia en las luchas protestatarias}

En su obra Castells roza un problema, pero que ni siquiera llega a plantear: la relación entre las protestas y la violencia. En un intento por explicar la violencia de la no-violencia, según él, de las movilizaciones de protesta, confunde violencia, que es una categoría socio-política y posible componente de las luchas sociales, con agresividad, que es una categoría psico-orgánica propia de la condición humana: el movimiento Occupy era mayoritariamente no violento, tanto en su filosofía como en la práctica. Pero era agresivo, porque su táctica de ocupar el espacio para establecer su autonomía y de manifestarse contra los modos funcionales del sistema estaba destinado a encontrarse con la acción policial (p. 186s).

Las razones para considerar como axioma del movimiento que la no violencia era fundamental (p.139) no sólo son injustificadas, sino que además contradicen el poder de las mismas movilizaciones de protesta. Considerar que las movilizaciones y las protestas se oponen a la violencia, al margen de las declaraciones de no-violencia que se puedan formular por los participantes, porque se trata de un principio básico de la nueva cultura de la paz y la democracia que el movimiento quiere difundir (p.130), es tan ingenuo e ilusorio como injustificable. Es precisamente contra esa cultura de la paz y la democracia, con las que se reviste y legitima el orden de la violencia económica en el mundo, contra las violencias y horrores económicos (V. Forrestier) del capitalismo, que las movilizaciones de ciudadanos protestan.

Cuando a inicios de los 90 las NNUU y el Banco Mundial ponen en circulación el imperativo y programa de la gobernabilidad fue para neutralizar el ciclo de protestas que generarían los gobiernos neoliberales y la gubernamentalidad de sus políticas económicas y la gobernancia del capitalismo financiero. El esquema o síndrome terrorista / antiterrorista una década después es análogo: no tanto destruir y suprimir todo posible terrorismo y terrorista sino proteger el nuevo orden económico antiterrorista global. 
Negar a las movilizaciones de protesta su potencial de violencia es despojarlas de su sustancia política y de la lógica del enemigo, ya no del adversario, al que hay que destruir. A diferencia de toda violencia instrumental, la protesta es portadora de una violencia sustantiva, precisamente porque es re-activa a esas otras violencias que la provocan.

Nada permite hablar de una cultura de la paz en un mundo transformado en campo de batalla de todas las guerras económica y antiterroristas; y mucho menos de una democracia convertida en su instrumento de legitimación. Por eso Castells comparte con las movilizaciones de protesta la creencia en la posibilidad de una democracia ya, real, participativa, cuando de hecho no hay otra democracia posible en las modernas sociedades de mercado; sólo transformando el modelo de sociedad neoliberal sería posible cambiar su modelo de gobierno democrático. Si la democracia representativa (liberal) ha fracasado en la sociedad de mercado (neoliberal), esta misma sociedad impediría con mucha más fuerza y razón posibles modelos de democracia participativa.

Al pensar en términos de movimientos sociales las movilizaciones de protesta, Castells atribuye a éstas la no-violencia de aquellos. De otro lado, no reconocer la violencia inherente a las protestas, supone ignorar esas otras violencias mayúsculas o más poderosas, contra las que precisamente las protestas se movilizan. La violencia policial no responde tanto a la violencia de las protestas cuanto a la defensa del ordenamiento global de la violencia en el mundo.

Al no disponer de una particular teoría de la violencia en las luchas colectivas y en las protestas políticas, Castells no puede establecer una diferencia pero tampoco continuidad entre una protesta desarmada, como fueron las movilizaciones en Europa, EEUU e incluso en Túnez, y una protesta armada, que llegó a convertirse en guerra civil (en Libia y Siria). Así mismo desconocer la violencia inherente a la protesta impide a Castells diferenciar entre una violencia armada y una violencia desarmada, y por consiguiente el hecho que no haya solución de continuidad entre la violencia de protestas más o menos desarmadas.

Las movilizaciones de protesta se encuentran atrapadas en una inexorable contradicción: sin reivindicaciones y sin ejercer su potencial de violencia dichas movilizaciones terminan debilitándose sin lograr cambio alguno; pero si su violencia transgrede los umbrales imaginarios del orden económico dominante, las protestas corren el riesgo de ser criminalizadas y declaradas terroristas. No hay que dejarse engañar por la ideología política de la tergiversación: no es el terrorismo ni los terroristas que han convertido al nuevo orden económico global en un régimen antiterrorista, sino más bien lo contrario: es su antiterrorismo lo que mejor legitima y con más fuerza preserva ese nuevo ordenamiento capitalista del mundo. ${ }^{7}$

Estos, no otros son los efectos contradictorios de la violencia (p. 216); por eso no se puede reducir la violencia a la represión que las protes- 
tas provocan y mucho menos a un supuesto instinto de autodefensa (ibid.). Lo que explica el potencial de violencia de las protestas es el que ejerce el nuevo ordenamiento del capitalismo global; en otras palabras no es la violencia instrumental de la represión de las movilizaciones protestatarias sino la violencia estructural, que articula la protesta a la violencia del no hay alternativa al orden dominante neoliberal.

Las actuales movilizaciones de protesta en todo el mundo, con sus diversas morfologías y alcances, ponen de manifiesto un fenómeno nuevo al mismo tiempo que deshacen un esquema tradicional (que se remonta a Aristóteles y pasa por Maquiavelo): la oposición e incompatibilidad de la política y la violencia. Hasta ahora la política ponía fin a la violencia y la violencia era el más allá o más acá de la política; hoy la violencia ha dejado de ser una cualidad o instrumento de la política para convertirse en su forma y contenido.

\section{Una versión demasiado ética y sentimental de las protestas}

Otro de los registros dominantes en el libro de Castells son las interpretaciones éticas y afectivo sentimentales, quizás muy californianas, de las movilizaciones de protesta. Lo que se explica por una deficitaria versión política del fenómeno. Ya el título de la obra es muy sintomático. Indignación y esperanza pertenecen al repertorio de los sentimientos y las pasiones; es decir de la inacción y por ello carentes de virtud política. Dentro de lo que sería una psicología del poder tanto la indignación como la esperanza inhiben la acción política y contribuyen a debilitar al sujeto político.

Para Maquiavelo, quien quizás como pocos profundizó en la psicología del poder, los sentimientos y las pasiones (desde las morfologías del temor y el miedo hasta las esperas y esperanza), son patologías políticas, que impiden o pervierten la acción del político. Se suele ignorar con frecuencia una fundamental ecuación política, según la cual cuanto peor es la realidad presente tanto mayor es la tentación utópica y tanto más fuerte la generación de esperanzas: es tanta la distancia entre cómo se vive y cómo se debería vivir, que aquel que deja aquello que se hace por lo que se debería hacer, aprende más bien la ruina que su salvación ( $E l$ príncipe, c. 15).

Castells despliega un manejo muy simple y arbitrario de estos sentimientos, y deja al lector muy perplejo ante cómo la humillación unió a aquellos que transformaron el miedo en indignación y la indignación en esperanza (p. 20). Todavía más sorprendente parece el sostener que los movimientos sociales son movimientos emocionales (p. 30). Los movimientos reivindicativos son sociales, las movilizaciones de protesta son políticas, sus componentes sentimentales, por otro lado no fáciles de observar, harían referencia a una psicología de las masas, a la fuerza o violencia de las mismas reivindicaciones y protestas, pero de ninguna manera es el componente afectivo el que define la acción colectiva. 
Es precisamente una confusa y muy simple psicología de las masas, la que parece llevar al autor a un manejo demasiado mecanicista y casi automático de las pasiones, que supuestamente movilizan las protestas, cuando considera el proceso de acción colectiva arraigado en la indignación, impulsado por el entusiasmo y motivado por la esperanza (p. 32). Una cosa es que la acción colectiva, como toda acción humana, se encuentre investida de múltiples y diversos sentimientos, y otra cosa muy diferente sostener que estos explican y son la causa de la acción social o política.

Este quid pro quo, de confundir lo objetivo y subjetivo de una acción, se reitera a lo largo de todo el texto: según el autor a partir de las condiciones objetivas surgieron las emociones y sentimientos y estos sentimientos produjeron protestas (p. 43). Se trata obviamente de un proceso inverso: las condiciones objetivas producen las movilizaciones de protesta, investidas eso sí de afectos y sentimientos. Por eso resulta insostenible, por mucho que se apele a la neurociencia social, el afirmar que el cambio social tiene un motivo emocional como todo comportamiento humano (p.210).

¿Cómo se articulan y combinan la ira y el miedo que desencadena la ansiedad, el cual se superaría en la acción comunicativa, y que de nuevo se pasa a la ira? ¿Qué entender por motivos emocionales de la acción social, cuando las emociones son cualidades de la acción y no un motivo exterior a ella y que la moviliza? Estos interrogantes suscitan mucha incredulidad sobre el uso de esta tan singular hermenéutica de las pasiones por parte de Castells, con la que más bien parece compensar la falta de otras explicaciones más coherentes y adecuadas el fenómeno de las movilizaciones de protesta.

Todo este género de explicaciones supone desconocer lo que Touraine llama la desarticulación de la acción colectiva, cuando el exceso de las ideologías y de la misma acción política en relación a la realidad económica genera una movilización social más ficticia que real, más teatral que eficaz (1988:469). Y en la medida que la protesta se vuelve ética, afectiva y mediática se niega a sí misma su propio potencial de violencia y de fuerza política, es decir se vuelve ineficaz e inofensiva.

\section{La ambigua movilización en las redes y la protesta mediática}

Si hay un tema principal en esta última obra de Castells ese son las redes sociales. Hasta tal punto que el mismo título de su obra las personaliza y hace protagonistas (redes de indignación y esperanza), y constantemente parece referirse a las redes sociales como la causa y explicación de las movilizaciones de protesta. Siendo las redes sociales el gran tema del pensamiento y obra del autor (La sociedad en redes, t. 1, 1996; La era de la información, t. 2, 1997), se entiende que las redes de la información y comunicación se conviertan en el principio de interpretación de un fenómeno social tan relevante como son los movimientos protestatarios.

Ahora bien, que internet y las redes sociales hayan contribuido a las 
movilizaciones de protesta por todo el mundo no permite exagerar sus efectos e influencias. ${ }^{8}$ Más bien ha ocurrido lo contrario: el déficit de efectividad de las movilizaciones de protesta intentó ser compensado por un exceso de expresividad, lo que supuso una importante complicidad mediática: las protestas se prestaron a una extraordinaria exposición mediática y los massmedia por su parte amplificaron la espectacularidad de las protestas.

Y si Castells corre el riesgo de sustituir lo social por la web y el internet y la telefonía digital, reduciendo todas las formas de socialidad a la conectividad en las redes, nada extraño que en no pocos pasajes de la obra supedite de la acción colectiva a la eficacia de las redes. De la misma manera que piensa la sociedad desde las redes y no éstas desde lo social, así también parece pensar las movilizaciones de protesta desde las redes y no éstas desde aquellas. Por ejemplo, no son las redes que excluyen los liderazgos, como pretende el autor: como son una red de redes no necesitan un liderazgo y un centro de mando ni tampoco una organización vertical (p.212).

La verdadera razón socio-política es otra: a diferencia de los movimientos sociales, que requieren la conducción de un determinado sector social y una organización coherente de sus reivindicaciones, las movilizaciones de protesta son producto de una re-acción colectiva (en términos tourainianos) y de una convergencia de grupos y sectores sociales heterogéneos unidos ocasionalmente por una protesta o constelación de protestas; ya que es la misma protesta que moviliza sin necesidad de una conducción ni organización, y cifrando su fuerza precisamente en su heterogénea y centrífuga inorganicidad. Siendo anti-sistema las movilizaciones de protesta no pueden ser más que anti-sistémicas a su interior.

El problema de fondo es por consiguiente político: la extraordinaria exposición mediática de las movilizaciones de protesta, conscientes de que existen más en la virtualidad de las redes y de los mass-media que en la realidad histórica y social, cuentan con la cómplice cobertura de los massmedia, que por razones de explotación y rentabilidad mediáticas no políticas amplifican la dramaturgia de las protestas.

Cuando Castells habla de un movimiento en red (p. 170) no sólo sugiere que las movilizaciones y protestas tienen lugar en la red y son producto de ellas. Internet y las redes de telefonía móvil no son simples herramientas, sino formas de organización, expresiones culturales y plataformas específicas de autonomía política (p. 108s). Que sean formas de intercambio de información y contacto, de convocatoria y encuentro, ello no significa que la conectividad de las redes garantice una real comunicación, vínculos y solidaridades. Por otro lado, Castells insiste más de una vez en la autonomía política, a la que dan lugar las redes: El espacio de autonomía es la nueva forma espacial de los movimientos sociales en red (p. 213). ¿En qué autonomía se está pensando? ¿Una autonomía política meramente virtual? El autor es enfático: Internet como 
todas las tecnología es una plataforma privilegiada para la construcción de la autonomía social (p.218).

Esta declaración tan hiperbólica podría prestarse a una interpretación crítica, según la cual es en la red, donde los individuos se vuelven autónomos unos de otros, haciendo de ella el lugar sustitutivo de las sociedades e instituciones sociales, donde mejor y de manera indolora se vive la ruptura de los vínculos sociales. No otra sería esa cultura de la autonomía, donde los individuos pueden al fin sobrevivir los unos sin los otros, en contacto pero sin compromisos ni solidaridades entre ellos. Lo que en gran medida ocurre en el happening de las protestas.

Y lo de happening no es simple metáfora. Ya Touraine se refería a los actores sin acción, cuando hablaba de un exceso de autonomía de las ideologías e incluso de la acción política respecto a la realidad económica, acarreando una movilización social y política más ficticia que real, más teatral que eficaz (1988:469).

\section{Conclusión: ¿Quiénes son los propietarios de las redes sociales?}

Cuando tanto se habla de autonomía de y en las redes, de una tecnología de la libertad, de las redes en cuanto lugares y productores de autonomía de sus usuarios, siendo obvia esta pregunta Castells no se la plantea: ¿quiénes son los dueños de las redes sociales?

Interrogarse sobre los propietarios de las redes sociales se ha vuelto un asunto grave y urgente: cuando (Febrero, 2013) precisamente el Consejo de la Unión Europea se dispone a aprobar una ley que proteja la privacidad de los usuarios de Internet y de las redes sociales, se ha desatado una de las mayores y más encarnizadas guerras de lobbys de todos los tiempos, ya que se trata de un oceánico número de empresas en todo el mundo que viven de la publicidad y marketing en la red a costa de la privacidad de los ciudadanos y sin que estos lo sepan, la cual es además objeto de explotación ilimitada por gigantescas tecnologías (El País). Es en estas circunstancias que aparece el verdadero Big Brother de las redes sociales, y cómo sus usuarios no serían más que clientes y comparsas de los Mercados globales.

Los grandes inventores de Internet y sus redes, convertidos en las grandes fortunas del mundo, siguen siendo sus propietarios y controlando sus desarrollos; de ninguna manera ha sido la cultura de la libertad a nivel social y la cultura de la individualidad y la autonomía a nivel de los actores sociales que dieron lugar a las redes de Internet (p. 222).

No deja de ser una cruel paradoja que los propietarios de las redes sociales en todo el mundo, con sus fabulosas fortunas, todas sus empresas e industrias, con sus monopolios y encarnizadas competitividades entre ellos, sus evasiones fiscales, hayan contribuido en gran medida a la exclusión y el empobrecimiento de tantos obreros, empleados y profesionales en todos los países, siendo muchos de ellos los que se movilizan y protestan. Que las 
redes sean instrumentos de las movilizaciones de protesta no significa que sean aliadas.

A la cuestión de ¿quién gobierna internet? Dan Schiller responde las multinacionales y los super-Estados pero no ciertamente los usuario; mientras aquellos amasan fortunas y gobiernan el mundo, haciendo de las redes una máquina de vigilancia, estos se conectan, se informan, trabajan y se divierten; pero no más: el control de Internet garantiza la supremacía americana en el ciberespacio, en el plano comercial y militar. ${ }^{9}$ 
Polis, Revista Latinoamericana, Volumen 12, $N^{\circ}$ 35, 2013

\section{Notas}

${ }^{1}$ Cfr. Slavoj Zizek, Occupy: Scenes form Occupied America, Verso, 2011; Thomas Frank, Occuper Wall Street, un mouvement tombé amoureux de lui-même, Le Monde Diplomatique, n. 706, janvier, 2013.

${ }^{2}$ Manuel Castells, The Rise of the Network Society, Blackwell Publishers, Oxford, 1996; The Information Age: Economy, Society and Culture, vol. II, The Power of Identity, Blackwell Publishers, Cambridge, 1997.

${ }^{3}$ Lenny Flank, Voices From 99 Percent: An Oral History of the Occupy Wall Street Movement, Red Black \& Publishers, Florida, 2011.

${ }^{4}$ Cfr. J. Sánchez Parga, Del conflicto social al ciclo político de la protesta, en Ecuador Debate, n. 64, abril 2000.

${ }^{5}$ Eran tan heterogéneos los sectores sociales movilizados contra el presidente Gutiérrez, y que provocaron su derrocamiento, que para dotarse de una identidad se apropiaron la acusación de forajidos, que el mismo presidente les había propinado.

${ }^{6}$ Cfr. Amartya Sen, Inequality Reexamined, Clarendon Press, Oxford, London, 1992.

${ }^{7}$ Cfr. Sánchez Parga, J., El nuevo orden antiterrorista mundial, en Ecuador Debate, n. 60, diciembre 2003.

${ }^{8}$ Una excelente crítica del fenómeno en el caso particular de los levantamientos árabes ofrece el libro de Yves González-Quijano, Arabités numériques. Le printemps du Web árabe, Sinbad- Actes Sud, Arles, 2012.

${ }^{9}$ Dan Schiller, Qui gouvernera Internet?, Le Monde Diplomatique, n. 707, fevrier, 2013. 


\section{Bibliografía}

Castells, Manuel (1996), The Rise of the Network Society, Blackewell Publishers, Oxford.

Ídem (1997), The Information Age: Economie, Society and Culture, vol. II, The Power of Identity, Blackwell Publishers, Oxford / London.

Flank, Lenny (2011), Voices From 99 Percent: An Oral History of the Occupy Wall Street Movement, Red Black \& Publishers, Florida.

Frank, Thomas (2013), “Occuper Wall Street, un mouvement tombé amoureux de lui-même”, Le Monde Diplomatique, n. 706, janvier.

González-Quijano, Yves (2012), Arabités numériques. Le printemps du Web árabe, Sinbad- Actes Sud, Arles.

Machiavelli, Nicoló (1992), Il Principe. Tutte le Opere, Edit. Sansoni, Firenze.

Sánchez Parga, J. (2000), “Del conflicto social al ciclo político de la protesta”, en Ecuador Debate, n. 64, abril.

Ídem (2003), “El nuevo orden antiterrorista mundial”, en Ecuador Debate, n. 60, diciembre.

Schiller, Dan (2013), “Qui gouvernera Internet?”, Le Monde Diplomatique, n. 707, fevrier. SEN,Amartya (1992), Inequality Reexamined, Clarendon Press, Oxford / London.

Touraine, Alain (1988), La parole et le sang. Politique et société en Amérique Latine, Odile Jacob, Paris.

Zizek, Slavoj (2011), Occupy: Scenes form Occupied America, Verso. 